\title{
BANKING INVESTMENT LENDING IN CONDITIONS OF IMBALANCES OF MOVEMENTS OF FINANCIAL RESOURCES
}

\author{
Alina HERASYMENKO ${ }^{1}$ \\ Higher State Educational Institution "Banking University", Ukraine
}

\begin{abstract}
The purpose of the paper is to justify theoretically the existence of disparities between the paces of development of the financial and real sectors of the economy of Ukraine, and in this regard, to study of the role of the banking investment lending as a credit instrument in managing imbalances of movement of financial resources. The hypothetico-deductive method allows us to investigate the causes of occurrence of disparities between the rates of development of the financial and real sectors of the Ukrainian economy. The method of analysis allows us to investigate the penetration rate of bank credit mechanisms in the past five years (2011-2015) in the processes of financing of the needs of the real sector for capital investments. Methodology. The survey is based on the theoretical analysis of the scientific literature in order to identify the causes of imbalances of movement of financial resources, the result of their influence on the pace of development of the real and financial sectors of the economy. The work displays the main approaches to the definition of the term of "financialization". Different points of view of scientists about the impact of financialization on investment processes and the flow of financial resources are grouped in this article. Also, there are presented visions of the major economic schools on the interaction of financial and real sectors of the economy. On the basis of special non-fiction the author of this research worked out the simplified scheme of imbalances of movement of financial resources in the economy. Also, in this article are studied the theoretical basis of bank investment lending, and is justified its role in managing the process of convergence of the financial and real sectors of the economy. Results of the survey showed that the cause of the imbalances of movement of financial resources is the processes of financialization. This process leads to distortion of the key role of the financial sector, which is to serve the real sector. Banking investment lending may be an effective mechanism for the convergence of the financial and the real sector. However, the result of analysis has shown that it does not work in modern conditions. Practical implications. The theoretical and practical analysis can be the basis for future research, especially with regards to the reasons of non-usage of banking investment lending as a tool of the control of imbalances of movement of financial resources in terms of prevailing financial sector relative to the real. Value/ originality. The results of the study make it possible to provide a better understanding of the role and practical importance of banking lending as a tool of investment in real sector, which is used by banks with the purpose to control the motions of financial resources.
\end{abstract}

Key words: economy, financial sector, real sector, imbalances, banking investment lending.

JEL Classification: G21, G24, G31

\section{1. Вступление}

Переход Украины от централизованной экономики к рыночной модели ведения хозяйства в послеАние Аесятилетия породии множество Аиспропорций межАу отраслями экономики. Финансовому сектору экономики Украины удамось приблизиться к рыночным стандартам ведения и организации бизнеса, тогда как реальный сектор так и не смог обеспечить свою конкурентоспособность и эффективность. Несбалансированные темпы развития финансового и реацьного сектора экономики стаци оАной из основных причин возникновения разрыва межАу спросом производственных преАприятий на инвестиционный капитал и действующего предложения финансового. Существенная роль в этих процессах принадлежит финансиализации экономики. Аисбаланс Авижения финансовых, в том числе и инвестиционных, ресурсов в условиях превалирования финансового сектора экономики наА реальным сектором, усугубляет ситуацию относительно критично высокой степени износа основных фондов производственных преАприятий, их низкого технологического уровня и высокой энергоемкости производства. В свою очереАь, эти проблемы также препятствуют эффек-

\footnotetext{
Corresponding author:

${ }^{1}$ Department of Finance and Credit, Higher State Educational Institution "Banking University”.

E-mail: al_gerassi@meta.ua
} 
тивному развитию отраслей переработки и выпуска готовой продукции. Украинские предприятия продолжают экспортировать дешевое сырье в страны-производители, вместо того, чтобы экспортировать отечественную продукцию по мировым рыночным ценам.

Проблемы Аиспропорций межАу отраслями экономики Украины можно разрешить при условии устранения Аисбалансов Авижения финансовых ресурсов, главным образом, путем более рационального распределения инвестиционного капитала между финансовым сектором экономики и реальным. В связи с этим, целью статьи явцяется теоретическое обоснование Аиспропорций межАу темпами развития финансового и реацьного секторов экономики Украины и, в этой связи, исследование роли банковского инвестиционного кредитования как креАитного инструмента управления Аисбалансами Авижения финансовых ресурсов.

\section{2. Аисбаланс Авижения финансовых ресурсов: Причины и послеАствия}

Безусловным катализатором возникновения Аисбалансов Авижения финансовых ресурсов в экономике явмяются процессы финансиализации, которые характеризируются опережающим развитием финансового сектора в отличие от реального, активным перетеканием капитала в финансовую сферу, распространением деятельности финансовых посредников, увеличением количества финансовых инструментов и спектра операций с их участием.

Финансиализация - закономерный продукт глобализации. «Современная экономика, - отмечают исследователи, - это, прежде всего финансовая рыночная экономика» (Byukenen Dzh. M.,
Masgreyv R.A., 2004; Raevskiy D.Yu., 2012). УтвержАение и развитие послеАней имеет своим императивом финансиализацию (financialization). Этот термин бым впервые официально использован в 2009 г. в Аокладе ЮНКТАА (Trade and Commodity Report), в котором присутствовац специальный раздел - «The Financialization of Commodity Report» (The Financialization of Commodity Report, 2009).

Анализ основных научных подходов к трактовке понятия «финансиализация» Аает возможность выделить их основные группы (табл. 1).

По мнению автора, финансиализация - это объективная траектория развития финансовой сферы Аеятельности, которую определяют конкретные экономические условия, в которых, за счет увеличения количества финансовых инструментов, популяризации операций с фиктивным капиталом и миберализации финансовых отношений, обеспечивается сокращение сроков получения прибыли при вложениях на финансовых рынках по сравнению с инвестициями в реальные активы.

Процес финансиализации является веАущим фактором, который определяет развитие экономики. Особенно, учитывая то, что этот процесс существенно искажает роль финансов, которая, в илеале, Аолжна заключаться в обслуживании реацьного производства, обеспечивая аккумумяцию, гибкость, эффективное распределение и перераспределение стоимостей в экономике. ОАнако, современное гипертрофированное развитие финансовой сферы, напротив - ведет к росту неравенства населения в Аоходах, Аолгосрочного сокращения совокупного спроса, неэффективного распределения финансовых ресурсов, падения реацьного сектора, неравномерного развития

Таблица 1

Научные подходы к опреАелению сущности понятия «финансиализация»

\begin{tabular}{|c|c|c|c|}
\hline $\begin{array}{l}\text { Наименование } \\
\text { научного подхода }\end{array}$ & & Суть научного подхода & Авторы \\
\hline \multirow[t]{2}{*}{ Акционерный подхоА } & \multirow{2}{*}{$\begin{array}{l}\text { Финансиализация } \\
\text { как категория }\end{array}$} & $\begin{array}{l}\text { которая определяет ориентацию на } \\
\text { акционерную стоимость как режим } \\
\text { корпоративного управления }\end{array}$ & В. Аазоник, М. О Самливан \\
\hline & & $\begin{array}{l}\text { которая определяет повышения роли рантье в } \\
\text { экономике }\end{array}$ & Аж. Смизин, О. Орхангази, Т. Пемми \\
\hline \multirow{2}{*}{$\begin{array}{l}\text { Внутрихозяйственный } \\
\text { подхоА }\end{array}$} & \multirow{2}{*}{$\begin{array}{l}\text { Финансиализация } \\
\text { как процесс }\end{array}$} & $\begin{array}{l}\text { влияния на внутренние процессы } \\
\text { функционирования субъектов хозяйствования }\end{array}$ & Р. Бэтт \\
\hline & & трансформации экономики & Г. Магдоф, П. Свизи \\
\hline $\begin{array}{l}\text { Гегемонистический } \\
\text { подход }\end{array}$ & \multicolumn{2}{|c|}{$\begin{array}{l}\text { Финансиализация как стремительный рост Аоли финансового } \\
\text { сектора в экономике }\end{array}$} & $\begin{array}{l}\text { О. Орхангази, Е. Штокхаммер, } \\
\text { Аж. Епштейн, В.С. Аукьянов }\end{array}$ \\
\hline ПоАход накапливания & \multicolumn{2}{|c|}{$\begin{array}{l}\text { Финансиализация как способ получения прибыли и вовмечения } \\
\text { инвестиций }\end{array}$} & $\begin{array}{l}\text { Г. Криппнер, В. Мимберг, Аж. Арриги, } \\
\text { П. Аос Сантос, С. Аапавитсас }\end{array}$ \\
\hline $\begin{array}{l}\text { Инновационный } \\
\text { подхоА }\end{array}$ & \multicolumn{2}{|c|}{$\begin{array}{l}\text { Финансиализация как результат активного развития финансовой } \\
\text { торговли и расширения спектра финансовых инструментов }\end{array}$} & К. Филипс, Ю. Осик, Н.О. Щепочкина \\
\hline
\end{tabular}

Источник: составлено автором на основе (Lazonick, W., 2000; Smithin, J., 1996; Orhangazi, O., 2008; Palley, T.I., 2007; Batt, Rosemary, 2012; Magdoff, H., 1987; Stockhammer, Engelbert, 2010; Orhangazi, Özgür, 2008; Epstein, G., 2005; Luk'yanov, V.S., 2013; Krippner, Greta, 2005; Milberg, W., 2008; Arrighi, G., 1994; Dos Santos, P., 2009; Lapavitsas, C., 2009; Phillips, K., 1996; Osik, Yu.I., 2014; Schepochkina, N.A., 2011) 
Таблица 2

Точки зрения разных ученых относитемьно вАияния финансиамизации на процессы инвестирования

\begin{tabular}{|c|c|}
\hline Краткое содержание точки зрения & Автор \\
\hline $\begin{array}{l}\text { Пока финансовые активы будут предлагать более высокую доходность, нежели реальные } \\
\text { инвестиционные проекты, до тех пор будет инвестировано больше именно в них. То } \\
\text { есть финансовые инвестиции будут вытеснять реальные. ОАнако все это не может Аолго } \\
\text { продолжатся на макроуровне, поскольку не возможно бесконечно наращивать прибыли } \\
\text { и при этом не подкрепмять ее производственными мощностями }\end{array}$ & Аж. Тобин \\
\hline $\begin{array}{l}\text { На протяжении периода финансиализации нефинансовые корпорации за счет } \\
\text { увеличения своих финансовых инвестиций вынуждены создавать или покупать } \\
\text { финансовые дочерние компании в связи с низкими прибылями от реального фактора }\end{array}$ & Аж. Кротти \\
\hline $\begin{array}{l}\text { Финансиализация заставила нефинансовые фирмы вести себя как участников } \\
\text { финансового рынка. То есть они отошли от своих предыдущих основ } \\
\text { функционирования направленных на Аолгосрочный рост за счет реального накопления } \\
\text { капитала. }\end{array}$ & Е. Штокхаммер \\
\hline $\begin{array}{l}\text { Несмотря на то, що финансиализация позволяет облегчить нефинансовым корпорациям } \\
\text { получение доступа на финансовый рынок, она также может поднять стоимость } \\
\text { капитала, Аелая его более дорогостоящим Аля привлечения денежных ресурсов с } \\
\text { финансового рынка. }\end{array}$ & Р. Бойэр \\
\hline $\begin{array}{l}\text { В развивающихся странах фирмы отАают предпочтение вкладывать в более ликвидные } \\
\text { оборотные активы на финансовом рынке, которые способны быстрее принести } \\
\text { ожидаемый доход, чем необоротные основные фонды }\end{array}$ & А. Торнем \\
\hline
\end{tabular}

Источник: составлено автором на основе (Tobin J., 1997; Crotty J., 2005; Stockhammer E., 2004; Boyer R., 2000; Tornell A., 1990)

Таблица 3

Взаимодействие финансового и реального секторов (точки зрения основных экономических школ)

\begin{tabular}{|c|c|c|c|c|}
\hline \multirow[b]{2}{*}{$\begin{array}{c}\text { Экономическая } \\
\text { шкома }\end{array}$} & \multicolumn{3}{|c|}{ Взаимодействие финансового и реахьного секторов } & \multirow{2}{*}{$\begin{array}{c}\text { Ромь финансового } \\
\text { сектора по отношению } \\
\text { к реальному }\end{array}$} \\
\hline & Кмючевые субъекты & $\begin{array}{c}\text { Инструменты } \\
\text { взаимодействия }\end{array}$ & Мотивы взаимодействия & \\
\hline Киассическая & $\begin{array}{l}\text { Финансовые посредники } \\
\text { (банки), фирмы }\end{array}$ & КреАитование & $\begin{array}{l}\text { Обеспечение } \\
\text { перераспределения } \\
\text { уже существующих } \\
\text { материамьных ценностей в } \\
\text { обществе }\end{array}$ & $\begin{array}{l}\text { Обслуживающе- } \\
\text { пассивная }\end{array}$ \\
\hline Марксизм & $\begin{array}{l}\text { Банки (как торговцы } \\
\text { ссудным капиталом) } \\
\text { и собственники } \\
\text { факторов производства } \\
\text { (как представители } \\
\text { промышиенного капитала) }\end{array}$ & КреАитование & $\begin{array}{l}\text { Обеспечение расширенного } \\
\text { воспроизводства }\end{array}$ & $\begin{array}{l}\text { Возможности } \\
\text { позитивного вАияния }\end{array}$ \\
\hline Неокиассическая & $\begin{array}{l}\text { Финансовые учреждения, } \\
\text { фирмы, домохозяйства }\end{array}$ & $\begin{array}{l}\text { Кредитование } \\
\text { и эмиссионное } \\
\text { финансирование }\end{array}$ & $\begin{array}{l}\text { Использование кредитных } \\
\text { среАств на ведения } \\
\text { экономической Аеятельности }\end{array}$ & $\begin{array}{l}\text { Возможности } \\
\text { минимизации рисков и } \\
\text { обеспечение доходности } \\
\text { вцоженного капитала } \\
\end{array}$ \\
\hline Кейнсианство & $\begin{array}{l}\text { Финансовые посредники } \\
\text { (банковские и небанковские } \\
\text { учреждения), фирмы, } \\
\text { Аомохозяйства }\end{array}$ & $\begin{array}{l}\text { КреАитование и } \\
\text { участие в капитаме }\end{array}$ & $\begin{array}{l}\text { Обеспечение } \\
\text { краткосрочного } \\
\text { и Аолгосрочного } \\
\text { инвестирования капитала }\end{array}$ & $\begin{array}{l}\text { Регулирование } \\
\text { экономической } \\
\text { Аинамики при условии } \\
\text { соответствующей } \\
\text { государственной } \\
\text { подАержке }\end{array}$ \\
\hline Институционамизм & $\begin{array}{l}\text { Финансовые посредники } \\
\text { (банковские и небанковские } \\
\text { учреждения), фирмы, } \\
\text { Аомохозяйства }\end{array}$ & $\begin{array}{l}\text { Кредитование, } \\
\text { участие в капитаме и } \\
\text { инвестициях }\end{array}$ & $\begin{array}{l}\text { Обеспечение } \\
\text { миквиАности, снижения } \\
\text { рисков и устранения } \\
\text { информационной } \\
\text { асимметрии на рынке }\end{array}$ & $\begin{array}{l}\text { Относительная } \\
\text { функциональная } \\
\text { самостоятельности и } \\
\text { автономность }\end{array}$ \\
\hline
\end{tabular}


стран и концентрации капитала в финансовых центрах, повышения рисков банкротства, Аестабилизации социально-экономического развития.

Следует отметить, что среАи ученых существуют размичные мнения относительно влияния финансиамизации на процессы инвестирования (табл. 2).

Принимая во внимание изложенное выше, процесс возникновения Аиспропорций межАу темпами развития финансового и реацьного секторов экономики возможно преАставить с помощью упрощенной схемы (рис. 1).

Исследуя вопрос об инструментах решения проблемы эффективного взаимодействия финансового и реального секторов экономики, обратимся к мнению преАставителей основных экономических школ относительно взаимодействия финансового и реацьного секторов (табц. 3) (Korneev, 2015).

Исходя из данных, изможенных в таблице 3, наиболее распространенным инструментом взаимодействия финансового и реального секторов экономики явцяется креАитование.

Учитывая Аоминирующие позиции банковского сектора в финансовой системе, как крупнейшего центра аккумуляции Аенежных ресурсов, ключевого участника в процессах трансформации и перераспределения финансового капитала, эффективным инструментом в решении проблемы конвергенции финансового и реального секторов экономики может выступить банковское инвестиционное креАитование (дамее - БИК).

\section{3. БИК в условиях Аисбаманса Авижения финансовых ресурсов}

Инвестиционное поле Аеятельности банков играет важнейшую роль в содействии эффективному функционированию экономики, поскольку инвестиции явмяются основой расширенного воспроизведения экономики, как в цемом, так и хозяйственной деятельности мюбого преАприятия, в частности.

По мнению Lutsiv B.L. (2001) функционирование банков на рынке инвестиций характеризируется тремя основными направлениями Аеятельности: осваивание инвестиций, участие в инвестировании, инвестирование.

В рамках инвестиционного направмения банк выполняет посреАнические функции, аккумулирует денежные ресурсы, реализовывает функцию сбережения и трансформации их в капитац, обеспечивает концентрацию и накопмение капитаха, выполняет работу с ценными бумагами, как за свой счет, так и за счет клиента. Исходя из этого, банк может быть как инвестором, так и кредитором. Следовательно, банковские операции можно сгруппировать слеАующим образом:

- инвестиционные и креАитно-инвестиционные операции (Аолевое участие в Аругих преАприятиях; создание дочерних структур; участие в финансовопромышиенных группах; андеррайтинг);

- кредитные операции (БИК).

Инвестиционный кредит особенный тем, что такой виА кредита направляется не на удовлетворение текущих потребностей ими приобретение уже созАанной стоимости, а на обеспечение послеАующего увеличения стоимости за счет строительства, реконструкции, модернизации, то есть создания новых мощностей сферы производства и оборота.

Mazurok P.P. (2010) и Guzenko O.P. (2010) разработали схематический поАхоА к пониманию категории «инвестиционное кредитование» (рис. 2).

Объектами инвестиционного кредита выступают товарно-материальные ценности и конкретные затраты, обусловленные расширенным воспроизведением. В частности, такими объектами явмяются объекты производственного и непроизвоАственного зна-

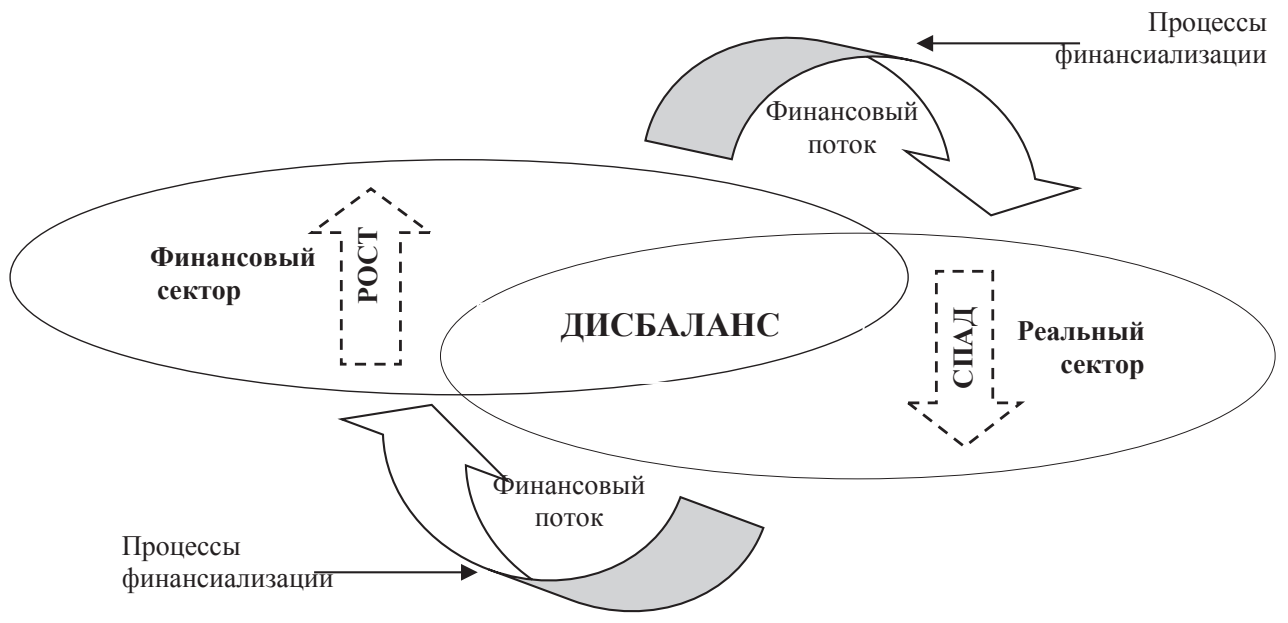

Рис. 1. Упрощенная схема Аисбахансов Авижения финансовых ресурсов в экономике

Источник: составлено автором 
чения, очереди строительства, пусковые комплексы, объекты строительства, новое строительство, расширение Аействующих предприятий, реконструкция Аействующих преАприятий, техническое перевооружение Аействующих преАприятий. Субъектами инвестиционного кредита явмяются креАиторы и заемщики (Gritsay, 2011; Peresada, Mayorova, 2002) .

В зависимости от роли в инвестиционном процессе, субъектов инвестиционного кредитования целесообразно разделить слеАующим образом:

- прямые участники: кредиторы, заказчики, инвесторы, страховые компании, гарантийные фонды, инжиниринговые и консалтинговые фирмы; - непрямые участники: центральные банки, органы исполнительной вмасти, государственные и приватные фонды подАержки инвестиционных проектов, Аругие отечественные и общественные организации.
Существует Ава основных уровня системы принципов БИК (Gritsay, 2011): общеэкономические принципы (срочности, возвратности, обеспеченности, платности и целевого характера использования) и еАиничные принципы банковского инвестиционного креАитования, которые исхоАят от сути инвестиционного кредитования и могут по-разному проявляться в конкретных кредитных операциях. К специфическим принципам БИК стоит отнести (Gritsay, 2011):

- принцип обоснования жизнедеятельности объекта кредитования;

- принцип участия в реализации инвестиционного проекта квалифицированных и надежных партнеров; - принцип учета и распределения рисков проекта;

- принцип урегулирования правовых аспектов и разработки конкретных скорректированных Аействий реализации инвестиционного кредитования.

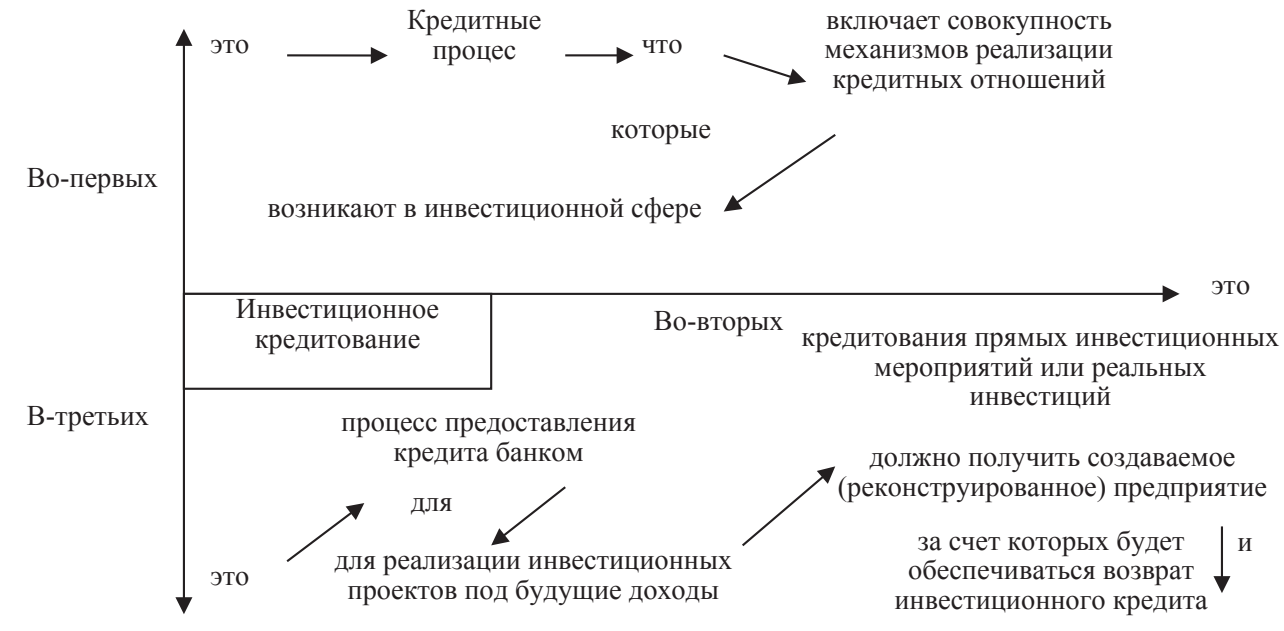

Рис. 2. Расширенное толкование категории «инвестиционное креАитование»

Таблица 4

Проникновение БИК в экономику Украины за послеАние пять Ает

\begin{tabular}{|c|c|c|c|c|c|c|}
\hline Показатемь & 2011 гоА & 2012 гоА & 2013 гоА & 2014 гон & 2015 гоА & $\begin{array}{l}\text { I квартал } \\
2016 \text { года }\end{array}$ \\
\hline Степень износа основных фондов, \% & 75,9 & 76,7 & 77,3 & 83,5 & - & - \\
\hline Капитальные инвестиции, мин. грн., в т.ч.: & 259932,3 & 263727,7 & 247891,6 & 204061,7 & 251154,3 & 51591,7 \\
\hline за счет банковских кредитов и других ссуд, \% & 16,3 & 16,1 & 14,8 & 8,8 & 7,3 & 7,6 \\
\hline $\begin{array}{l}\text { за счет собственных средств предприятий и } \\
\text { организаций, \% }\end{array}$ & 58,6 & 59,2 & 63,4 & 71,5 & 67,4 & 73,5 \\
\hline $\begin{array}{l}\text { КреАиты, выданные банковским сектором } \\
\text { Украины, млн. грн., в т.ч.: }\end{array}$ & 825320 & 815327 & 911402 & 1006358 & 965093 & 983944 \\
\hline $\begin{array}{l}\text { кредиты, выданные на приобретение, } \\
\text { строительство и реконструкцию недвижимости } \\
\text { (всего), \% }\end{array}$ & 1,25 & 0,92 & 1,43 & 1,54 & 1,35 & 1,35 \\
\hline $\begin{array}{l}\text { кредиты, выданные на приобретение, } \\
\text { строительство и реконструкцию недвижимости на } \\
\text { срок более } 5 \text { лет, \% }\end{array}$ & 0,66 & 0,45 & 0,60 & 0,75 & 0,61 & 0,54 \\
\hline
\end{tabular}

Источник: составлено автором на основе (Osnovni pokazniki diyalnosti bankiv Ukrayini, 2011-2016rr.; Vartist osnovnih zasobiv, 2000-2014rr.; Kaptalni Investitsiyi za dzherelami finansuvannya, 2011-2016) 
Соблюдение особенных принципов инвестиционного креАитования позволяет поднять эффективность операции и уменьшить ее риски.

По мнению автора, БИК - это креАитно-инвестиционная операция банка, которая предусматривает эффективное сотрудничество банка (как кредитора) и клиента (как заемщика), направленное на реализацию конкретного инвестиционного мероприятия, нацеленного на создание (расширение) новых (Аействующих) источников Аоходности. При этом очень важным явцяется оАновременное Аостижение экономического, социацьного и экологического эффекта после реализации креАитуемого инвестиционного проекта.

Принимая во внимание, изложенное выше, следует отметить, что сама суть операций БИК преАусматривает все необходимые возможности активного влияния на процессы Авижения финансовых ресурсов. Таким образом, эффективное использование механизма БИК путем перераспределения финансовых потоков из финансового сектора в реальный сектор экономики может быть Авижущей силой в поАнятии показателей ее деятельности.

Исследуем уровень проникновение БИК в процессы инвестирования капитальных инвестиций преАприятий за последние пять мет путем анализа отАельных показателей экономики Украины (табл. 4).

На основе Аанных таблицы 4 можно слелать вывоА, что за последние пять мет (2011-2015 гг.) и первый квартал 2016 г. проникновение БИК в процессы инвестирования капитальных инвестиций преАприятий Украины оставалось и остается на низком уровне. Увеличение износа основных фондов преАприятий Украины (на 10\% с 2011 г. по 2014 г.) свидетельствует об отсутствии Аостаточного финансирования капитальных вложений. Сегодня, как и в последние года, расходы, связанные с капитальными инвестициями преАприятий практически полностью покрываются за счет их собственных ресурсов. ОАнако, этого критически недостаточно Аля удовлетворения их потребности в модернизации. Участие банков в финансировании капитальных инвестиций преАприятий за периоА анализа практически не ощущается. Ситуация усугубцяется тем, что с 2013 г. по 2015 г. Аоля банковских креАитов и Аругих ссуА, направленных на финансирование капитальных инвестиций преАприятий снизимась более чем наполовину (на 54,65\%).

Аоля кредитов, выданных банковским сектором на приобретение, строительство и реконструкцию неАвижимости в УАельном весе креАитного портфеля банковского сектора остается незначительной около 1,5\% и меньше за период анализа. Аоля того же виАа креАитов, но на срок более пяти мет (оптималь- ный срок Амя освоения и обеспечения окупаемости инвестиций преАприятиями реального сектора) в УАельном весе креАитного портфеля банковского сектора - не превысила 0,75\% за период анализа.

Таким образом, можно сАелать вывоА, что БИК, которое по своей сути имеет все возможности выступить Аейственным инструментом решения вопроса конвергенции финансового и реального секторов экономики Украины - не работает.

Причины неэффективного использования БИК банковским сектором Украины как оАного из инструментов решения проблем финансовых дисбалансов заскуживают выступить в качестве объекта последующих исследований.

\section{4. ВЫводЫ}

Проблемы, связанные с возникновением и накапливанием финансовых Аисбалансов Украины можно минимизировать «изнури», при условии более жесткого регулирования Авижения финансовых ресурсов, в образовании Аисбалансов которых немамоважную роль играют процессы финансиацизации.

Учитывая то, что наиболее очевидным инструментом взаимодействия финансового и реального секторов экономики явмяется креАитование, целесообразно предположить, что именно банковскому сектору преАстоит внести свой значительный вклаА в разрешения сложившейся ситуации. Этому также способствуют превалирующие позиции банковского сектора в финансовой системе Украины, а также расширенный инструментарий банковских кредитных операций по сравнению с Аругими финансовыми институтами.

НеАооцененным инструментом в управлении Авижением финансовых потоков с целью нивелирования их Аисбалансов и, тем самым, запуска конвергенции финансового и реацьного секторов, по нашему мнению, остается банковское инвестиционное кредитование.

На основе результатов анализа относительно Аоли банковского инвестиционного кредитования в УАельном весе инвестирования капитальных инвестиций преАприятий Украины за послеАние пять мет, приходиться констатировать, что этот инструмент практически не использовался.

Таким образом, возникает вопрос о необходимости в Аальнейших исследованиях относительно уровня потенциала банковского сектора Украины в контексте возможностей креАитования инвестиционных целей преАприятий, а также относительно проблем, которые сдерживают активизацию банковского инвестиционного кредитования. 


\section{References}

Byukenen, Dzh. M., Masgreyv, R.A. (2004). Suspilni fInansi i suspilniy vibir: dva protilezhnih bachennya derzhavi / Per. $\mathrm{z}$ angl. - Kiyiv, Akademiya, 175 s.

Gritsay, T.L. (2002). Investitsiyi: praktika ta dosvid, № 14, s. 7-10.

Vartist osnovnih zasobiv u 2000-2014 rokah. Ofitsiyniy sayt Derzhavnoyi sluzhbi statistiki Ukrayini. Retrieved from: http://www.ukrstat.gov.ua/

Kaptalni Investitsiyi za dzherelami finansuvannya. Ofitsiyniy sayt Derzhavnoyi sluzhbi statistiki Ukrayini. Retrieved from: http://www.ukrstat.gov.ua/

Korneev, M.V. (2015). Metodologichni zasadi otsinyuvannya ta regulyuvannya disbalansiv ruhu finansovih resursiv v ekonomitsi Ukrayini: avtoref. dis. d-ra ekon. nauk: 08.00.08 / Korneev Maksim Valeriyovich; Ukr. akad. bank. spravi. - Sumi, 39 s.

Luk'yanov, V. S. (2013). Finansializatsiya yak proyav globalizatsiynih transformatsiy. Aktualni problemi ekonomiki, № 4(142), s. 15-23.

Lutsiv, B.L. (2001). Bankivska diyalnist u sferi investitsiy. - Ternopil: Ekonomichna dumka, kart-blansh, s. 320.

Mazurok, P.P. (2010). Naukovo-teoretichni peredumovi doslidzhennya vzaemozv'yazku kreditnoyi politiki vitchiznyanih bankiv iz protsesami investitsiynogo kredituvannya. Ekonomika, fInansi, pravo, № 7, s. 17-23.

Osik, Yu.I. (2014). Deglobalizatsiya mirovoy ekonomiki kak sledstvie ee finansializatsii. Mezhdunarodnyiy zhurnal prikladnih i fundamentalnyih issledovaniy, № 1, s. 202-205.

Osnovni pokazniki diyalnosti bankiv Ukrayini (2011-2016rr.). Ofitsiyne Internet-vidavnitstvo Natsionalnogo banku Ukrayini. Retrieved from: http://bank.gov.ua/control/uk/publish/article?art_id=34661442\&cat_ $\mathrm{id}=34798593$

Peresada, A.A., Mayorova, T.V. (2002). Investitsiyne kredituvannya: navch. posIb. - K.: KNEU, 271 s.

Raevskiy, D.Yu. (2012). Raskryitie ponyatiya «derivativ» v otechestvennoy praktike. Finansyi i kredit, № 39, s. 70-74.

Schepochkina, N. A. (2011). Osobennosti unifikatsii standartov regulirovaniya mirovogo finansovogo ryinka. Retrieved from: http://lomonosov-msu.ru/archive/Lomonosov_2011/1410/13300_1890.pdf

Arrighi, G. (1994). The Long Twentieth Century: Money, Power, and the Origins of Our Times. - London: Verso. Batt, Rosemary (April, 2012). The Impact of Financialization on Management and Employment Outcomes. 20th Annual John Lovett Memorial Lecture. - Ireland, University of Limerick, 29 p.

Boyer, R. (2000). Is a finance-led growth regime a viable alternative to Fordism? A preliminary analysis. Economy and Society, № 1, P. 111-145.

Crotty, J. (2005). The Neoliberal Paradox: The Impact of Destructive Product Market Competition and 'Modern' Financial Markets on Nonfinancial Corporation Performance in the Neoliberal Era, in Epstein, G. (ed.). Financialization and the World Economy. - Northampton, MA: Edward Elgar, p. 77-110.

Dos Santos, P. (2009). On the Content of Banking in Contemporary Capitalism. Historical Materialism, № 17(2), p. 180-213.

Epstein, G. (2005). Financialization and the World Economy. - London: Edward Elgar, 456 p.

Krippner, Greta (2005). The Financialization of the American Economy. Socio-Economic Review, Vol. 3, Issue 2, p. 173-208.

Lapavitsas, C. (2009). Financialised Capitalism: Crisis and Financial Expropriation. Historical Materialism, № 17(2), p. 114-148.

Lazonick, W. (2010). Maximizing shareholder value: a new ideology for corporate governance. Economy and Society, Vol. 29, № 1, p. 13-35.

Magdoff, H. (1987). Stagnation and the Financial Explosion. - New York, Monthly Review Press.

Milberg, W. (2008). Shifting sources and uses of profits: sustaining US financialization with global value chains. Economy and Society, № 37(3), p.420-451.

Orhangazi, O. (2008). Financialisation and capital accumulation in the non-financial corporate sector: A theoretical and empirical investigation on the US economy: 1973-2003. Cambridge Journal of Economic, № 32, p. 863-886.

Orhangazi, Özgür (2008). Financialization and the US Economy. - Northampton, Massachusetts: Edward Elgar Publishing.

Palley, T. I. (2007). Financialization: What It Is and Why It Matters. Levy Economics Institute Working Paper, № $525,31 \mathrm{p}$.

Phillips, K. (1996). Arrogant Capital: Washington,Wall Street, and the Frustration of American Politics. - New York, $320 \mathrm{p}$.

Smithin, J. (1996). Macroeconomic Policy and the Future of Capitalism: The Revenge of the Rentiers and the Threat to Prosperity. Aldershot.

Stockhammer, Engelbert (2010). Financialization and the Global Economy. University of Massachusetts Amherst Working Paper. Retrieved from: http://www.peri.umass.edu/fileadmin/pdf/working_papers/working_ papers_201-250/WP240.pdf 
Stockhammer E. (2004). Financialisation and the slowdown of accumulation. Cambridge Journal of Economics, Vol. 28, № 5, p. 719-741.

The Financialization of Commodity Report (2009). Retrieved from: http://www.businessmonitor.com.

Tobin J. (1997). The Macroeconomics of Savings, Finance and Investment. Comment, in Pollin, R. (ed.), Ann Arbor, University of Michigan Press, p. 1-8.

Tornell A. (1990). Real vs. financial investment: can Tobin taxes eliminate the irreversibility distortion? Journal of Development Economics, № 32, p. 419-444.

\section{Алина ГЕРАСИМЕНКО}

\section{БАНКОВСКОЕ ИНВЕСТИЦИОННОЕ КРЕДИТОВАНИЕ В УСЛОВИЯХ ДИСБАЛАНСОВ ДВИЖЕНИЯ ФИНАНСОВЫХ РЕСУРСОВ}

Аннотация. Целью работы является теоретическое обоснование диспропорций между темпами развития финансового и реального секторов экономики Украины, и в этой связи исследование роли банковского инвестиционного кредитования как кредитного инструмента при управлении дисбалансами движения финансовых ресурсов. Гипотетико-дедуктивный метод позволяет исследовать причины возникновения диспропорций между темпами развития финансового и реального секторов экономики Украины. Метод анализа позволяет исследовать уровень проникновения кредитных механизмов банка за последние пять лет (2011-2015 гг.) в процессы финансирования потребностей реального сектора в капитальных вложениях. Методика. Исследование основано на теоретическом анализе научной литературы с целью определения причин дисбалансов движения финансовых ресурсов, результата их влияния на темпы развития реального и финансового секторов экономики. В работе отображены основные подходы к определению сущности термина «финансиализация», сгруппированы точки зрения ученых относительно влияния финансиализации на процессы инвестирования и движения финансовых ресурсов, представлены видения основных экономических школ о взаимодействии финансового и реального секторов экономики. На основе обработанной научной литературы автором исследования была представлена упрощенная схема дисбалансов движения финансовых ресурсов в экономике. Исследованы теоретические основы банковского инвестиционного кредитования, а также обоснована его роль в управлении процессами конвергенции финансового и реального секторов экономики. Результаты исследования показали, что причиной возникновения дисбалансов движения финансовых ресурсов является процес финансиализации. Этот процесс приводит к искажению ключевой роли финансового сектора, которая заключается в обслуживании реального сектора. Механизмом конвергенции финансового и реального сектора может выступить кредитование. Учитывая доминантную роль банковского сектора в финансовой системе, эффективным инструментом при управлении дисбалансами движения финансовых ресурсов может выступить банковское инвестиционное кредитование. Однако результаты анализа относительно уровня проникновения банковского инвестиционного кредитования в процессы финансирования капитальных инвестиций предприятий на примере экономики Украины показали, что банковское инвестиционное кредитования не работает должным образом. Практическое значение. Проведенный теоретический и практический анализ может быть основой для будущих исследований, особенно это касается причин неиспользования банковского инвестиционного кредитования как инструмента управления дисбалансами движения финансовых ресурсов в условиях превалирования финансового сектора относительно реального. Значение/оригинальность. Полученные результаты исследования дают возможность обеспечить лучшее понимание роли и практического значения банковского инвестиционного кредитования как инструмента, который может использоваться банками в качестве эффективного механизма управления при урегулировании дисбалансов движения финансовых ресурсов в условиях превалирования финансового сектора относительно реального. Проведенный анализ уровня проникновения банковского инвестиционного кредитования в процессы финансирования капитальных инвестиций предприятий Украины дает основания полагать о существовании множества проблем комплексного характера, которые сдерживают развитие банковского инвестиционного кредитования. 